\title{
ESTELA DEL BRONCE FINAL HALLADA EN EL TÉRMINO DE ÉCIJA (SEVILLA)
}

\section{A LATE BRONZE AGE STELAE FOUND IN THE TERM OF ÉCIJA (SEVILLA)}

\author{
por \\ AURELIO PADILLA MONGE \\ EDUARDO VALDERRAMA JUAN ${ }^{1}$
}

RESUMEN Estela del Bronce Final hallada en las cercanías del arroyo del Berraco, en terrenos de la finca «El Berraco», situada en el término de Écija (Sevilla).

ABSTRACT Stele of the Late Bronze Age of the Iberian Peninsula found in the «El Berraco» estate, near of the Berraco stream, in the district of Écija (province of Seville).

La estela se halló, al parecer, en las cercanías del arroyo del Berraco, dentro de la cuadrícula definida por las coordenadas ${ }^{3} 25-{ }^{3} 26 /{ }^{41} 48-4147$ (Cartografía Militar de España; 1:50.000), en terrenos de la finca «El Berraco», propiedad del Sr. Don Joaquín Jiménez Roldán, situada en el término municipal de Écija (Sevilla). La estela fue trasladada y quedó depositada a pocos metros de uno de los muros exteriores del cortijo «El Berraco», en donde fue estudiada y fotografiada por uno de nosotros (E. Valderrama Juan). Posteriormente, la estela desapareció y hoy se halla en paradero desconocido.

El material empleado en la confección de la estela es un tipo de piedra caliza. La pieza no parece haber sufrido daños de importancia, salvo algunos desprendimientos periféricos. Sólo se aprecian dos zonas especialmente erosionadas; una se sitúa entre la cabeza de la figura humana y la espada; la segunda se ubica entre la mano derecha del guerrero -admitiendo su representación frontal- y el dibujo que interpretamos como «perro». También se observan tres fisuras -circunstancia nada extraña en las calizas- que recorren, de lado a lado, la zona dedicada a la representación figurada.

La estela, vista frontalmente, presenta una forma asimilable a un triángulo isósceles invertido, aunque con la base marcadamente curva. Debió de estar colocada en posición vertical, con el extremo puntiagudo introdu-

1. Universidad de Sevilla. 
cido en un hoyo excavado a tal efecto, como permite pensar el hecho de que la parte aguzada carezca de representación figurada. Dicha posición vertical era la más adecuada para que la estela cumpliera la función a la que presumiblemente estaba destinada, esto es, la de servir de señal visible, quizá aún sin carácter de hito fronterizo sensu stricto, en un paisaje en vías de conversión en territorio controlado por un jefe y su grupo de parentesco (Galán, 1993: 38).

Las medidas aproximadas de la estela son las siguientes: altura, $149 \mathrm{cms}$. (de los que 98,60 corresponden a la representación figurada); anchura máxima, que se alcanza en la parte superior, $81,75 \mathrm{cms}$. y anchura mínima, inapreciable, porque, como se dijo, la estela acaba en punta. Por último, el grosor oscila entre los 20 y los 25 centímetros.

Por lo que respecta al sistema de grabado, en las ocasiones en las que éste se reduce a un simple surco, es de sección en $\mathbf{U}$. El vaciado en extensión se emplea en las superficies amplias.

La composición se articula en torno a la imagen representativa del ser humano, que se constituye en protagonista indiscutible de la escena. Los restantes dibujos se disponen alrededor de esta figura central.

La figura humana se interpreta mediante trazos esquemáticos. La cabeza se concreta en el vaciado de un óvalo en el extremo superior del tronco, este último reducido a una estrecha franja de la que penden cuatro cordones que son las extremidades. Los brazos, tras arrancar de unos inexistentes hombros, desarrollan un arco de circunferencia de $90^{\circ}$ y adquieren la forma de dos líneas paralelas entre si y al tronco. Las piernas arrancan directamente del extremo meridional del tronco y conforman una horquilla invertida. Los pies se presentan como leves ensanchamientos extremos, mediante la ampliación pertinente del vaciado. Por último, las manos son las que reciben un tratamiento más analítico, pues se expresaron los cinco dedos. El guerrero se cubre con un casco adornado con una cornamenta liriforme.

Entre la cabeza del personaje y la espada, aparece un óvalo que puede interpretarse como espejo, aunque no se aprecie en la estela la parte del grabado correspondiente al mango, pues el lugar que éste debía de ocupar es uno de los dos que han sufrido una agresión lo suficientemente grave como para dejar irreconocible el primitivo diseño.

La espada, que se representa en posición vertical y con el mango cerca de la mano del guerrero, posee una hoja de tipo pistiliforme. La empuñadura puede interpretarse como maciza, con un pomo quizá en forma de seta y una guarda no muy amplia. En el caso de que así fuera, podríamos situarla dentro de la serie de las espadas de la ría de Huelva con este tipo de empuñadura (Fernández, 1988: 150-151); pero, también puede considerarse que refleja un tipo de empuñadura, con pomo rematado en incipientes apéndices, característica de las espadas del tipo «Hemigkofen» y sus derivaciones (Idem: 46-47), aunque con el enmangue tendente a formar una $\mathbf{V}$. Debemos reseñar que se halló un fragmento de espada de hoja pistiliforme en «El Santo Siervo» (o «Salto del Ciervo») I (Durán \& Padilla, 1990: 54), lugar muy cercano al del hallazgo de la estela, mientras que, aguas arriba del Genil, en el yacimiento de «Los Castellares» (Herrera), se encontró un ejemplar tipológicamente encuadrable en el grupo segundo de la clasificación de M. Almagro de las de la ría de Huelva (Tejera, 1976: 241-242).

La lanza, situada a la izquierda de la espada, con la punta hacia abajo, está resuelta mediante un trazo recto y algo ancho (el asta) que culmina en una hoja lauriforme. No se aprecia la existencia de regatón; éste, de existir, ocuparía una zona de la piedra hoy perdida. En relación a la lanza, debemos indicar el hallazgo, en el antedicho yacimiento de «Los Castellares», de una punta con paralelos en el depósito de la ría de Huelva (Tejera, 1976: 242) y similar a la grabada en nuestra estela.

La interpretación como «perro» del dibujo situado entre la punta de la lanza y la pierna derecha del guerrero se impone por exclusión y por analogía. En efecto, la presencia en la estela de un dibujo preferentemente interpretable como peine excluye que el grabado que tratamos en este párrafo también lo sea. Asimismo, la similitud que presenta el grabado en cuestión con los animales que tiran del carro induce a pensar que el 
grabador quiso reflejar la imagen de algún animal, quizá de menor tamaño que los anteriores. La imagen del animal se reduce a un trazo horizontal largo -el tronco- y seis trazos cortos verticales, correspondientes a la cola, la cabeza y las patas. Por coherencia general con los objetos y animales representados en la estela, característicos, por no decir exclusivos, de los guerreros de rango superior (Brunaux, 1986: 101-103), dicho animal no sería otro que el perro, ayudante y colaborador del hombre en una de las actividades más íntimamente vinculadas a la guerra y a los especialistas de la guerra, la caza. Por otra parte, parece existir un trazo entre la mano derecha del ser humano y uno de los extremos del perro. Cabe la posibilidad de que se trate de la representación de algún tipo de correa; pero, esta zona es una de las dañadas y es casi imposible reconocer el grabado que pudo haber.

Caballos y carro se sitúan en la parte inferior de la representación figurada, muy cerca de los pies del guerrero y del escudo, ocupando casi toda la anchura de la estela. La interpretación como «caballos» de las dos representaciones simétricas que tiran del carro es la más lógica y coherente, pues, la inexistencia o, al menos, la no apreciación de trazos que pudieran representar cornamentas excluye la posibilidad de que fueran bóvidos los animales que arrastran el carro. Por lo que respecta al vehículo, como en todas las representaciones de carros, la perspectiva del representado en nuestra estela es ingenua. La caja, vista desde arriba, muestra, quizá, las tablas del piso, mientras que su frontal no es exactamente curvo, como por el contrario ocurre en el caso de las restantes estelas con representaciones de carros. A pesar de su similitud general con otras cajas, la plasmada en nuestra estela es desmesuradamente larga en relación a las otras. Por su parte, las dos ruedas -que se representan vacías, por lo que puede pensarse que eran macizas- aparecen abiertas y levemente separadas de la caja, pero con trazos que reflejan la existencia de ejes. Los asideros también se presentan abiertos, pero están perfectamente unidos a la caja. El excesivo tamaño concedido a los asideros con respecto al resto del carro, circunstancia visible en nuestra estela y en otras que ha extrañado a no pocos estudiosos, podría responder al interés por definir el carácter de carro de guerra del vehículo, frente a otros carros de dos ruedas de utilidad no bélica, probablemente similares a los documentados a través de figurillas votivas de época posterior, que parecen reproducir vehículos dedicados al transporte de una o dos personas y, a veces, de alguna carga, que contaban con un asiento corrido en la parte posterior de la caja (Fernández-Miranda \& Olmos, 1986: 117-122) y que carecían de asideros posteriores. Para terminar con nuestro carro, diremos que el timón es triple y que el sistema de enganche parece ser un yugo.

El escudo, situado junto a la pierna izquierda del guerrero, está resuelto mediante tres circunferencias concéntricas y no presenta escotadura. En el centro aparecen dos líneas paralelas, que probablemente representen la manilla.

Por último, en la figura del peine, situado a la altura y cerca del hombro izquierdo del guerrero, son claramente perceptibles siete púas.

La combinación de elementos representados, esto es, escudo redondo, espada independiente de la figura humana, lanza, figura humana constituida en centro de la composición, casco de cuernos, espejo, peine, caballos y carro y animal no équido, y la ausencia de fíbula permiten incluir nuestra estela en el grupo 6 de los individualizados por E. Galán a partir del Análisis de Proximidades, es decir, en el de las estelas del valle de Guadalquivir (Galán, 1993: 46-50). Sin embargo, tanto desde el punto de vista de los elementos que aparecen reflejados como del de la disposición de los mismos, nuestra estela mantiene un paralelismo muy especial con la de Fuentedecantos, uno de los pocos ejemplares que han quedado sin agrupar después de la aplicación del Análisis de Proximidades. En efecto, ambas estelas, salvo por la presencia de cinco «cazoletas» en la de Fuentedecantos, son coincidentes en cuanto a los elementos representados y a las características de los mismos y en ambas, salvo en el caso del espejo, los elementos aparecen situados en un lugar similar, aunque el carro de la de Fuentedecantos tiene los caballos orientados hacia la derecha del observador. No debe excluirse que estemos ante un caso de pura coincidencia; pero, tampoco debe descartarse la posibilidad de que el 
empleo en ambos casos de casi los mismos elementos a la hora de expresar las ideas de prestigio y autoridad (Galán, 1993: 52) refleje la integración de los dos jefes representados en dichas estelas y, a través de ellos, de sus respectivos grupos, en un mismo circuito de intercambios, al menos -siguiendo la clasificación de Ch. D. Piot (1991)- en las Esferas Superior (mujeres) e Intermedia (riqueza), circuito en el que también estarían integrados los restantes grupos humanos del Medio y Bajo Guadalquivir.

Como monumento que probablemente refleja un creciente proceso de territorialización y sedentarización de los grupos humanos que habitaban los valles del Guadalquivir y Genil, podemos situar nuestra estela en el siglo IX a.C., o quizá en el VIII, en momentos anteriores a la aparición de los primeros poblados estables en dichos valles, fenómeno que comenzó a producirse en la segunda mitad del siglo IX y que se generalizó durante el siglo VIII (Escacena \& Belén, 1991; Durán \& Padilla, 1990: 46-55).

El lugar de hallazgo de la estela se sitúa al sur de Écija. Desde esta población y hasta el límite de su término en dirección a El Rubio, el paisaje se ondula, respondiendo a la presencia de depresiones que, en algunos casos, pueden ocupar una gran extensión. Las altitudes en estos parajes se alejan poco de los 160 metros sobre el nivel del mar, aunque aquí se alcanza la máxima del término, con los 307 metros del cerro de Palomarejo. Los aportes del Pleistoceno cubrieron gran parte del término, mientras que los aluviones del Genil sólo constituyen una estrecha faja, dando lugar a excelentes tierras de cultivo que atraviesan el término en dirección este-centro-norte. Igual sucede con los aluviones del arroyo Blanco, al cual acompañan desde el límite del término hasta su desembocadura en el Genil. Como resultado de su historia geológica, los suelos dominantes en el paisaje son los constituidos por margas amarillentas y grises, calizas blancas muy deleznables, calizas silíceas de color pardo amarillento algo más compactas y materiales arenosos y arenolimosos con cantos rodados, que a veces forman conglomerados muy compactos. A ambos lados del Genil afloran también margas pardoamarillentas que originan terrenos suavemente ondulados. Los depósitos cuaternarios de arcillas y limos calizos han formado excelentes tierras de cultivo conocidas vulgarmente como «tierras de bujeo».

Las potencialidades agropecuarias del entorno inmediato del lugar de hallazgo de la estela parece que fueron aprovechadas desde antiguo, pues, en los lugares conocidos como «Salinas de la Torre» $\mathrm{y}$ «El Santo Siervo» (o «Salto del Ciervo») I, situados en las cercanías del cortijo «El Berraco», se han detectado indicios de poblamiento calcolítico y del Bronce Inicial y, posteriormente, del Bronce Final (Durán \& Padilla, 1990: 39, 54), mientras la misma finca «El Berraco» y los muy cercanos lugares de «Don Rodrigo», «Los Motimentos», «Salinas de Borreguero» y nuevamente «Salinas de la Torre» han dado indicios de poblamiento romano (Durán \& Padilla, 1990: 75, 84, 104, 111).

Por otra parte, los nombres de los cercanos lugares de «Salinas de Borreguero»y «Salinas de la Torre»y los del arroyo Saladillo y del arroyo de la Saladilla, que desagua en el anterior y del que es afluente el arroyo del Berraco, se relacionan directamente con la existencia de importantes depósitos de sal, cuya explotación hasta el siglo XIX está perfectamente documentada (Sánchez, 1988: 196), mientras que la existencia de poblados del Bronce Final en las cercanías de ambas salinas permite pensar que su aprovechamiento también se produjo por aquellos momentos.

El proceso de territorialización y sedentarización provocó, entre otras consecuencias, la paulatina fijación de los niveles de prestigio, autoridad y riqueza y el aumento de la importancia de las actividades guerreras como medio de defensa del territorio en vías de ser controlado. Así, todos los objetos y seres presentes en la estela revelan la pertenencia del individuo reflejado en la piedra al restringido grupo de los guerreros de rango superior, personaje que, a través de la representación en la estela de dichos enseres y animales, hacía ostentación de su capacidad guerrera, frente a grupos a los que quería comunicar sus propósitos de explotar exclusivamente un territorio controlado por él y su grupo de parentesco; el espejo y el peine, en cuanto elementos empleados por el guerrero en el aderezo personal previo a la lucha (Chic, 1994: 278); el casco, la espada, la lanza, el escudo y el carro, en cuanto instrumentos directamente relacionados con la guerra sólo poseídos por 
la minoría capacitada para agenciarse tan caro armamento (Brunaux, 1986: 101-103); los cuernos del casco, en cuanto expresión de prestigio exclusiva de unos pocos individuos dentro de sociedades que seguían considerando la ganadería de bóvidos la actividad más prestigiosa (Padilla, 1991: 15; Sáez, 1993: 41) y el perro, como se dijo, en cuanto colaborador del hombre en la caza, una de las actividades más íntimamente ligadas a la guerra y a los especialistas en la guerra de rango superior.

El creciente control sobre el territorio señalizado por nuestra estela y, presumiblemente, por otras supuso la explotación en exclusiva, por parte de un grupo de parentesco, de las potencialidades agropecuarias del terreno y, probablemente, de alguno de los antedichos depósitos de sal, artículo que pudo utilizarse, junto con el ganado, en intercambios correspondientes a la Esfera Intermedia (Galán, 1993: 64-65), realizados con otros grupos de parentesco más o menos alejados.

\section{BIBLIOGRAFÍA}

BRUNAUX, J. L. (1986): Les Gaulois. Sanctuaires et rites. París.

CHIC, G. (1994): "Las estelas del suroeste hispano y el arreglo corporal del guerrero", Lengua y Cultura en la Hispania Prerromana. Actas del V Coloquio sobre Lenguas y Culturas Prerromanas de la Península Ibérica. Salamanca: 273-279.

DURÁN, V. \& PADILLA, A. (1990): Evolución del poblamiento antiguo en el término municipal de Écija. Sevilla.

ESCACENA, J. L. \& Belén, M. (1991): "Sobre la cronología del horizonte fundacional de los asentamientos tartésicos", Cuadernos del Suroeste: 9-33.

FERNÁNDEZ, M. C. (1988): Arqueología protohistórica de la península Ibérica (siglos X a VIII a.C.). Madrid.

FERNÁNDEZ-MIRANDA, M. \& OLMOS, R. (1986): Las ruedas de Toya y el origen del carro en la península Ibérica. Madrid.

GALÁN, E. (1993): Estelas, paisaje y territorio en el Bronce Final del suroeste de la península Ibérica. Madrid.

PADILlA, A. (1991): "Aproximación a la economía de Asido (Medina Sidonia, Cádiz) y su comarca en época orientalizante", Habis 22: 7-17.

PIOT, Ch. D. (1991): "Of Persons and Things: Some Reflections on African Spheres of Exchange", Man 26.3: 405-424.

SÁEZ, P. (1993): "La ganadería extremeña en la antigüedad", Actas del Simposio «Transhumancia y Cultura Pastoril en Extremadura». Badajoz: 37-49.

TEJERA, A. (1976): "El yacimiento tartésico de Los Castellares (Herrera, Sevilla)", Habis 7: 241-244.

SÁNCHEZ, R. (1988): “Écija en los informes de 1824”, Actas del I Congreso sobre Historia de Écija. Sevilla: 195-201. 

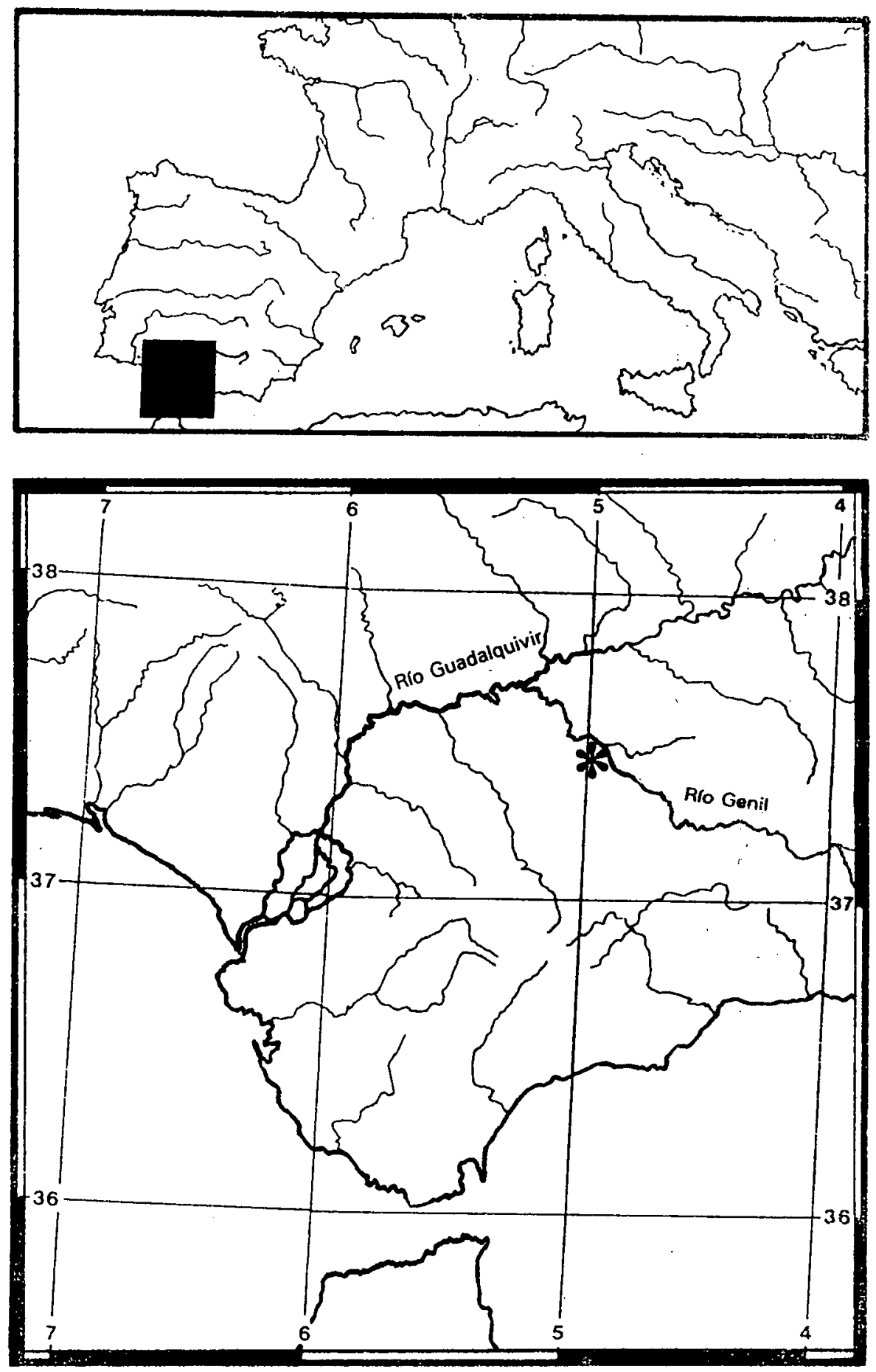

Fig. 1. Lugar de hallazgo de la estela. 


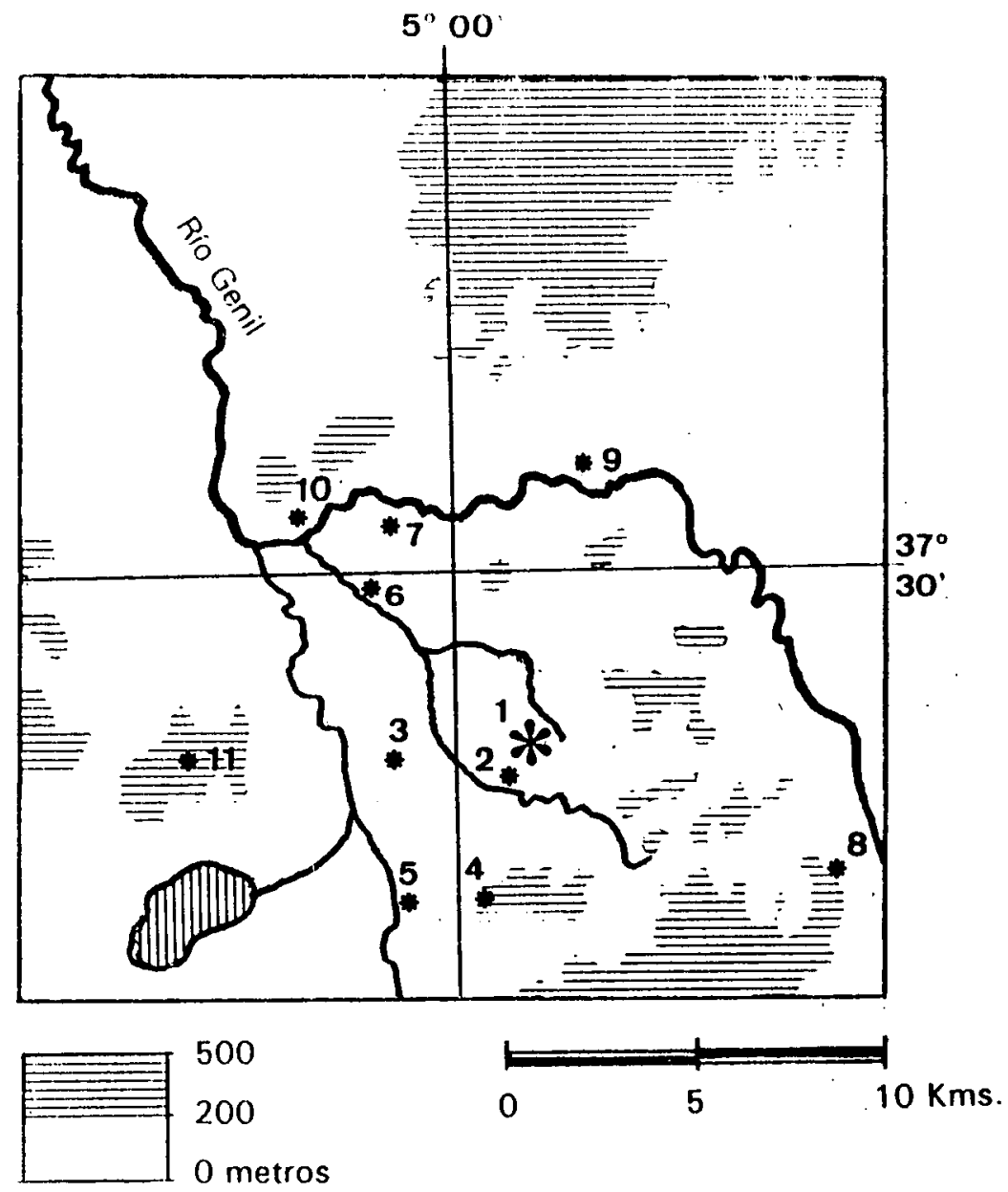

Fig. 2. Lugares con restos del Bronce Final situados en torno al lugar de hallazgo de la estela, dentro de un radio de acción de $10 \mathrm{kms}$.:

1.- Estela.

2.- «Salinas de la Torre».

3.- «Santo Siervo» (o «Salto del Ciervo») I.

4.- «Fuentidueñas».

5.- «Los Cosmes».

6.- «Zayuelas».

7.- «El Batán».

8.- «Castillo de Alhonoz».

9.- «Sotillo Gallego».

10.- «El Castillejo».

11. - «a Alcuza». 


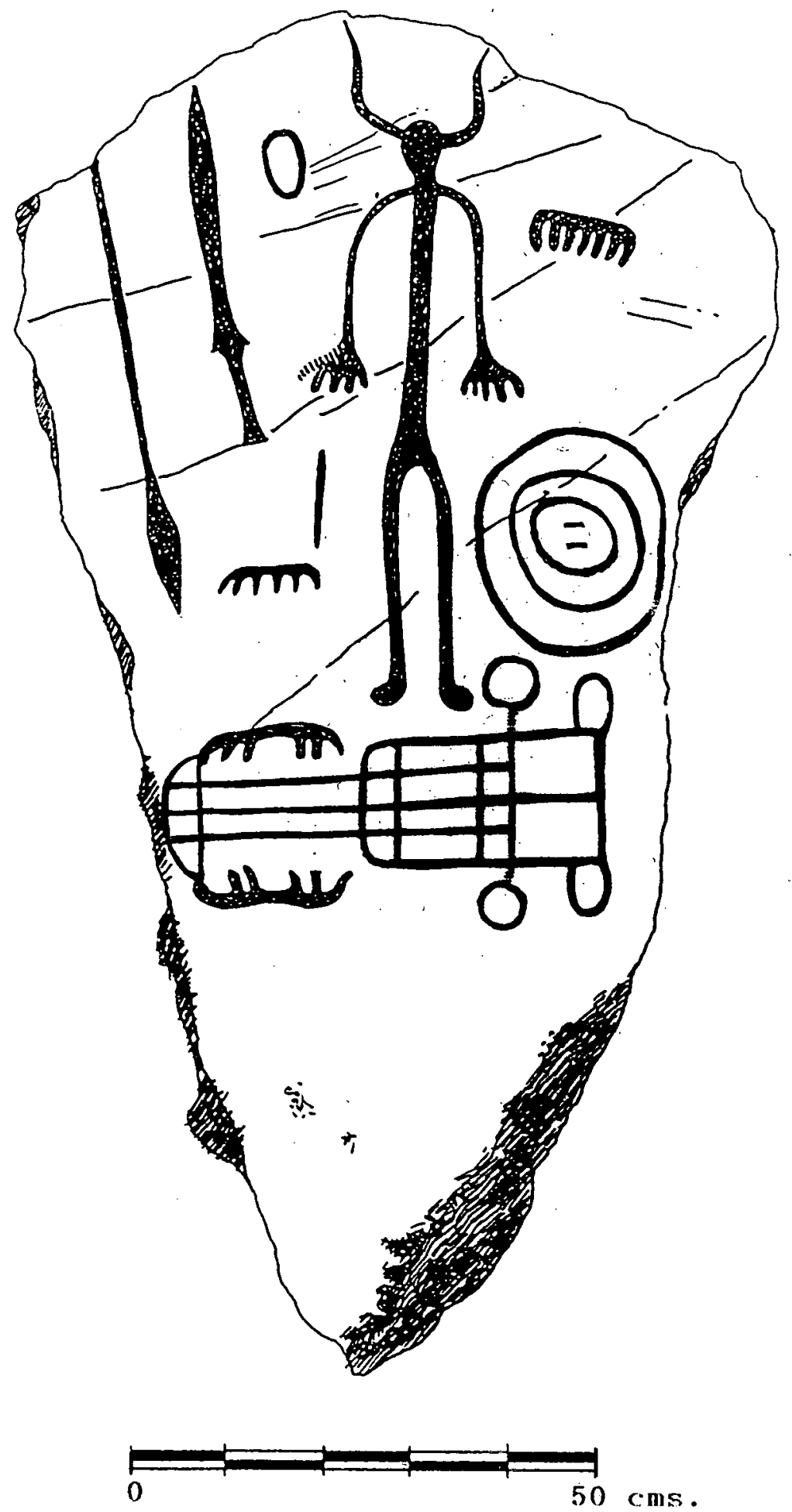

Fig. 3. Estela del Bronce Final hallada en la finca «El Berraco» (Écija, Sevilla). 